\title{
Investigation some physicochemical properties, lipids, glycerides and fatty acid composition of mulberry (Morus alba L) seed oil of three different regions of Bangladesh
}

\author{
Md. Munsur Rahman ${ }^{1}$, Ayesha Akther ${ }^{1}$, Md. Moinuddin ${ }^{1}$, Mst. Sarmina Yeasmin ${ }^{1}$, \\ Md. Mizanur Rahman ${ }^{1}$, Md. Saifur Rahman ${ }^{2,}$, Shawkat Ara Ferdousi ${ }^{2}$, M. Abu Sayeed ${ }^{2}$ \\ ${ }^{1}$ BCSIR Laboratories, Binodpur Bazar, Rajshahi-6206, Bangladesh \\ ${ }^{2}$ Department of Applied Chemistry and Chemical Engineering, Rajshahi University, Rajshahi-6205, Bangladesh
}

\section{Email address:}

saifur_13bd@yahoo.com (M. S. Rahman)

\section{To cite this article:}

Md. Munsur Rahman, Ayesha Akther, Md. Moinuddin, Mst. Sarmina Yeasmin, Md. Mizanur Rahman, Md. Saifur Rahman, Shawkat Ara Ferdousi, M. Abu Sayeed. Investigation Some Physicochemical Properties, Lipids, Glycerides and Fatty acid Composition of Mulberry (Morus Alba L) Seed oil of three Different Regions of Bangladesh. American Journal of Applied Chemistry.

Vol. 2, No. 3, 2014, pp. 38-41. doi: 10.11648/j.ajac.20140203.11

\begin{abstract}
The physicochemical properties, glycerides, lipids and fatty acid compositions of mulberry (tut) seed oil have been studied. It was observed that tut, a shrub grown well under the soil and climatic conditions of Bangladesh contains $31.41 \%$ of orange yellow colored oil. The oil was fractionated into mono, di and triglycerides by silicic acid column chromatography. The triglyceride was varied from $90.08-91.05 \%$, diglyceride from $3.25-4.10 \%$ and monoglyceride from $1.47-2.05 \%$. The total lipids were fractionated into three major lipid groups, neutral lipids, glycolipids and phospho-lipids by silicic acid column chromatograpy. The neutral lipid ranges from 92.97-93.10\%, glycolipids from $2.12-2.43 \%$ and phospholipid from $1.85-1.92 \%$ of the total oil of the lipid applied. Saturated and unsaturated fatty acids present in the oil were separated and the amount varied from 15.04-16.28\% and 74.29-75.86\%, respectively, depending on soil conditions of the areas in which the plant grows. The percentage of fatty acid compositions of the oil were analyzed by GLC and found to contain linoleic acid (74.29\%), palmitic acid (10.60\%), stearic acid (5.61\%) and myristic acid (0.07\%).
\end{abstract}

Keywords: Mulberry (Morus Alba L.) Seed Oil, Glyceride and Lipid Compositions, Column Chromatography, Saturated and Unsaturated Fatty Acid, GLC

\section{Introduction}

The plant mulberry (Morus alba L.) commonly known as 'Tut' in our country and largely grown under the soil and climatic conditions of Bangladesh. It belongs to the family Moraceae and genus Morus. In 2012-2013 about 27,000 MT of mulberry were produced in Bangladesh [1]. Mulberry is grown extensively for leaves used for rearing silkworms as mulberry leaves are the only source of food for silkworms. The fruit is cooling and laxative; it is used for sere throat, dyspepsia and melancholia. A large quantity of oils and fats, whether for human consumption or for industrial purposes, is presently derived from plant sources [2]. However, the mulberry seeds contain $25-35 \%$ yellow colored oil [3]. Linoleic acid is an essential fatty acid which cannot be produced by the human body and is accepted as being an ant carcinogenic substance. Deficiency symptoms include dry hair, hair loss and poor wound healing [4]. Mulberry seed oil is very rich in linoleic acid and it may be a valuable source of dietary fat. Since the composition of oil varies with the source, and depends on factors such as climatic conditions, region of cultivation, genetic and agronomic factors and by their interactions [5].

So the objective of this study is to extract oil from mulberry (Morus alba L.) seeds collected from three different districts of Bangladesh and to evaluate the physicochemical characteristics, lipid, glyceride and fatty acid compositions. 


\section{Materials and Methods}

Ripe and Mature fruits of mulberry are collected from the districts Rajshahi, Dinajpur and Jessore in the month of May-June (2012). Seeds were washed with water to remove foreign materials, dried in the sunlight for fifteen consecutive days and finally dried at $105^{\circ} \mathrm{C}$ for three hours by an electric oven. Dried seeds were ground into powder by using grinding machine and dried in an oven at a temperature of $105^{\circ} \mathrm{C}$ for an hour and oil was extracted in a soxhlet apparatus with n-hexane as solvent for about 6 hours. The extracted solvent was removed by using a rotary vacuum evaporator and the percentage of oil content was computed.

The oil was kept in air tight container at $4^{\circ} \mathrm{C}$ in a refrigerator. All chemicals and reagents were Merk (Darmstad, Germany) and BDH (Poole, England), silica gel (60-120 mesh) and silica gel $\left(\mathrm{HF}_{254}\right)$.

The specific gravity of the oil was calculated at $29^{\circ} \mathrm{C}$ with the help of a pycnometer. Refractive index of the clear oil was estimated at $29^{\circ} \mathrm{C}$ using Abe Refractometer following IUPAC [6] method. Chemical characteristics i.e., iodine value was determined by the hanus method, unsaponifiable matter was determined by the method depicted by Devine (1961) [7], while the saponification value, percentage of free fatty acid (FFA), and peroxide value were determined according to the methods described by Williams (1966) [8].

\subsection{Separation of Glycerides}

The oil was separated into mono-, di and tri-glycerde on silicic acid (E. Merck, Darmstad, Germany 70-230 mesh) column. The silicic acid was activated at $120^{\circ} \mathrm{C}$ overnight and again for 1 hour immediately before the column was prepared. Then, the silicic acid was hydrated with $5 \%(\mathrm{~N} / \mathrm{N})$ water. Slurry of $25 \mathrm{~g}$ of silicic acid in chloroform was poured into the column $(2.2 \mathrm{~cm}$ i.d), $1 \mathrm{~g}$ oil was dissolved in $15 \mathrm{~mL}$ of chloroform and quantitatively transferred to the column. The triglycerides were eluted with $200 \mathrm{~mL}$ of benzene, diglycerides with $200 \mathrm{ml}$ of a 1:9 (v/v) mixture of di-ethyl ether and benzene and monoglyceride with $200 \mathrm{~mL}$ of diethyl ether [9]. The elution was controlled of a flow role of 1.5-2.0 $\mathrm{mL} \mathrm{min}^{-1}$. The elution of each fraction was checked by thin layer chromatography (TLC) to ensure uniformity of separation of each class of glyceride. The eluted solvents were collected in a weighted flask. The fractions thus obtained were evaporated in a rotary vacuum evaporator and were dried under reduced pressure before being weighted. The percentages of these fractions were determined by gravimetric method.

\subsection{Separation of Lipids}

The major lipids of the oil were separated by silicic acid (E. merck, Darmstad, Germany, 70-230 inch) column chromatography [10]. The silicic acid was washed with water and methanol to remove fines and impurities. It was then activated at $120^{\circ} \mathrm{C}$ overnight and again for 1 hours before the column was prepared. Slurry of $25 \mathrm{~g}$ silicic acid in chloroform was powder into the column (2.2 i.d). 150 $\mathrm{mg}$ of the oil lipid was dissolved in $5 \mathrm{ml}$. eluting solvent and transferred to the column. Neutral lipid was eluted with chloroform, glycolipid with acetone and phospholipids with methods [11]. The elution was controlled at flow rate of $0.50-1.0 \mathrm{ml} / \mathrm{min}$. The elution of each fraction was monitored by micro-slide TLC to ensure uniformity and separation of each lipid class. The eluted solvents were collected in weighed flask. The fraction thus obtained were evaporated in a rotary vacuum evaporator and dried under reduced pressure before being weighed. The percentage of these fractions was estimated by gravimetric method.

\subsection{Separation of Saturated and Unsaturated Fatty Acids Present in the Seed Oil}

Separation of saturated and unsaturated acids were carried out by lead salt ether method on about $50 \mathrm{~g}$ of oil [12]. The oil was saponified with alcoholic caustic soda to obtain soap solution. A slight excess of lead acetate solution was added to the soap solution to form lead salt of fatty acids which were then separated. Ether was added to the mixture of lead salts and the whole mixture was hailed and cooled to $0^{\circ} \mathrm{C}$ for 24 hours. The lead salts of the unsaturated fatty acids were obtained by removing the ether from etheral solution. Each group of lead salts were suspended in water and treated with sufficient hydrochloric acid to liberate fatty acids from lead salt. On evaporating the ether, the fatty acids were obtained in separate groups. Finally masses of saturated and unsaturated fatty acids were obtained by weighing them separately.

\subsection{Analysis of Fatty Acid Composition of Oils}

Fatty acid compositions present in the oil of Rajshahi district sample was analyzed as their methyl esters which prepared by the Boron trifluride methanol method [13]. A GCD PYE Unicam gas chromatograph equipped with a flame ionization detector was used to determine the fatty acid methyl esters. Nitrogen carrier gas was used at a flowrate of $30 \mathrm{ml} / \mathrm{min}$. Fatty acids were separated on a $1.8 \mathrm{~m} \times$ $2 \mathrm{~mm}$ i.d. glass column packed with $6 \%$ BDS (Butanediol succinate polyesters) on solid support, Anakrom ABS 100/120 mesh Analysis was carried out at isothermal column temperature of $190^{\circ} \mathrm{C}$, injector and detector temperature for all GLC analysis were $230^{\circ} \mathrm{C}$. The peaks were identified by comparison with standard methyl esters with respect to retention times by plotting the log of retention time against equivalent carbon length (ECL). The peak areas were determined by multiplying peak height by width at half height. The percentage of each peak was calculated as the percentage of the total area of all the peaks. 


\section{Results and Discussion}

The solvent extraction of mulberry seed yielded $31.41 \%$ orange yellow colored oil (Table 1). The results are in accordance with Xiaolan et al (1998) [14]. There are no significant differences in the physicochemical properties of the oil samples collected from three different districts. The specific gravity and refractive index are very stable parameters and should be used for checking the identity of oils. It is observed that the specific gravity and refractive index of the mulberry seed oil were comparable with other important vegetable oils [15]. The high iodine value and saponification value is more or less similar to safflower seed oil $[16,17]$. Peroxide values of non-edible oil were in the range of $4.36-9.82$ m.eq. $/ \mathrm{kg}$ [18]. Oils having high percentages of peroxide are unstable and grow rancid easily [19]. The peroxide value of the mulberry seed oils (Table 1) were in comparable to other vegetable oil. The \% FFA value is in agreement with black mulberry (Morus nigra L.) seed oil [20]. From the results it's evident that mulberry seed oil contain small amount of unsaponifiable matter such as steroids tocopherols and hydrocarbons etc.

As shown in Table 2, mono, di and triglyceride contents

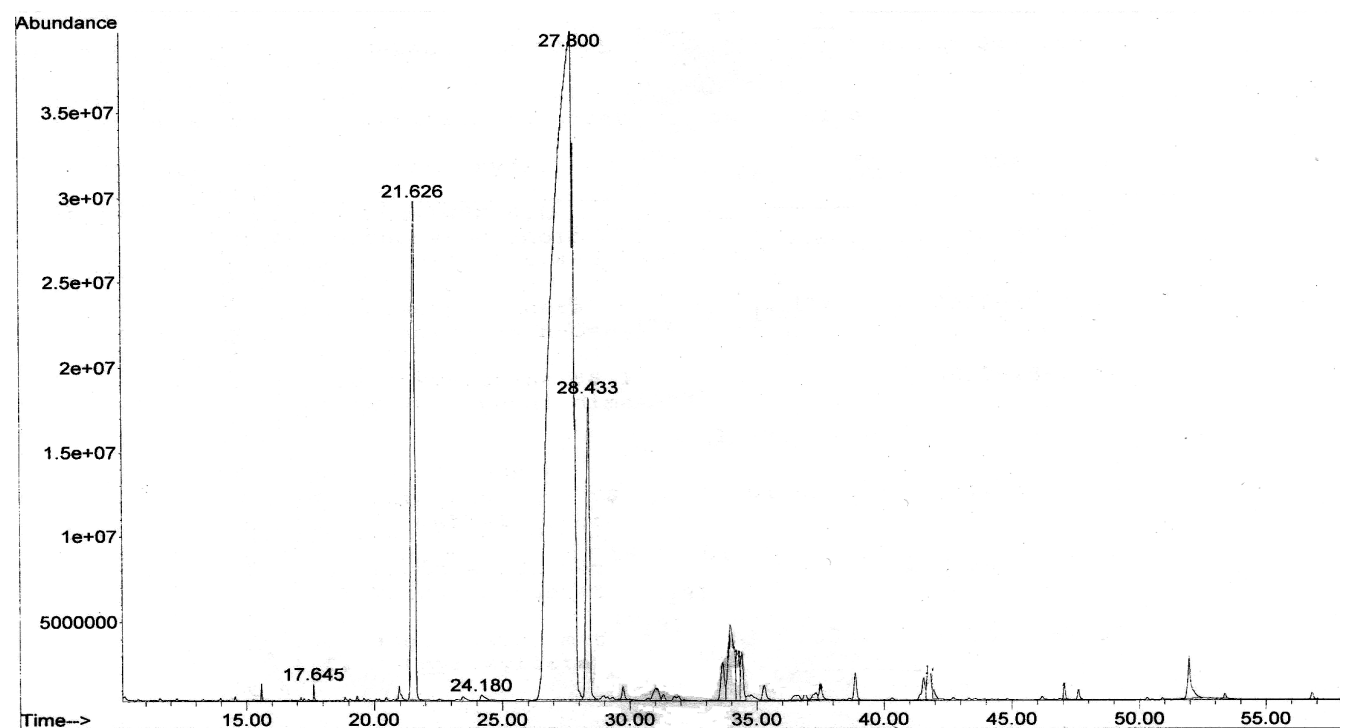

Figure 1. Gas liquid chromatogram of the fatty acid methyl esters mixture of mulberry seed oil collected from Rajshahi region.

\begin{tabular}{llll}
\hline \multirow{2}{*}{ Characteristics } & \multicolumn{3}{l}{ Origin of seeds } \\
\cline { 2 - 4 } & Rajshahi & Dinajpur & Jessore \\
\hline Percentage of oil & 31.16 & 32.14 & 30.95 \\
Specific gravity at $29^{\circ} \mathrm{C}$ & 0.918 & 0.915 & 0.917 \\
Refractive index at $29^{\circ} \mathrm{C}$ & 1.468 & 1.465 & 1.469 \\
Iodine vale & 150.04 & 147.35 & 146.51 \\
Saponification value $(\mathrm{mg}$ & 186.04 & 188.2 & 187.9 \\
KOH/g) & 2.15 & 2.34 & 2.20 \\
Free fatty acids $(\%)$ as oleic & 1.84 & 1.65 & 2.05 \\
Peroxide value (meg/kg) & 1.13 & 1.05 & 0.95 \\
Unsaponifiable matter $(\%)$ & & \\
\hline
\end{tabular}

Mean value of three experimental results
Table 1. Physical and chemical characteristics of mulberry seed oil. were estimated to be range from $1.47-2.05 \%, 3.25-4.10 \%$ and $90.08-91.05 \%$, respectively. Mulberry seed oil were separated into three major lipid groups such as neutral lipids, glycolipids and phospholipids as give in Table 2 . The results indicate that there is no significant difference in glyceride and lipid compositions among three samples collected from three different areas.

The saturated and unsaturated fatty acids present in the oil were separated by lead-salt ether method and the results are depicted in Table 2. It is seen that the percentage of saturated and unsaturated fatty acids present in the oil collected from the three different districts are almost similar.

The fatty acid compositions of the oil were determined by GLC showed in Fig. 1 and is documented in Table 3. It showed that the unsaturated fatty acids present in the oil are mainly linoleic $\left(\mathrm{C}_{18: 2}\right)$ acid, $74.29 \%$ which are more or less similar to safflower seed oil $[16,17]$ and also black mulberry (Morus nigra L) seed oil [20]. Thus the seed oil is a good source of the essential fatty acid, linoleic acid. The saturated fatty acids present in the oil are myristic $\left(\mathrm{C}_{14: 0}\right) 0.07 \%$, palmitic $\left(\mathrm{C}_{16: 0}\right) \quad 10.60 \%$ and stearic $\left(\mathrm{C}_{18: 0}\right) 5.61 \%$ as shown in table 3 and Fig. 1, respectively, which are in agreement with black mulberry (Morus nigra $\mathrm{L}$ ) seed oil [20]. (wt \%)

\begin{tabular}{llll}
\hline Composition & Rajshahi & Dinajpur & Jessore \\
\hline Monoglyceride & 1.47 & 1.82 & 2.05 \\
Diglyceride & 4.10 & 3.90 & 3.25 \\
Triglyceride & 90.08 & 90.75 & 91.05 \\
Neutral lipid & 92.97 & 93.40 & 93.10 \\
Glycolipid & 2.12 & 2.25 & 2.43 \\
Phospholipid & 1.85 & 1.90 & 1.92 \\
Saturted fatty acid & 16.28 & 15.92 & 15.04 \\
Unsaturated fatty acid & 74.29 & 74.52 & 75.86 \\
\hline
\end{tabular}

Mean value of three experimental results 
Table 3. Fatty acid composition (\%) of mulberry seed oil of Rajshahi variety (wt \%)

\begin{tabular}{ll}
\hline Fatty acid composition & Percentage \\
\hline Myristic acid $\left(\mathrm{C}_{14: 0}\right)$ & 0.07 \\
Palmitic acid $\left(\mathrm{C}_{16: 0}\right)$ & 10.60 \\
Stearic acid $\left(\mathrm{C}_{18: 0}\right)$ & 5.61 \\
Linoleic acid $\left(\mathrm{C}_{18: 2}\right)$ & 74.29 \\
\hline
\end{tabular}

\section{Conclusion}

The present study showed that the mulberry (Morus alba L) seed contain above $30 \%$ oil. Also, the present study reveals that there is no important variation in the physicochemical characteristics of the extracted oil of mulberry (Morus alba $\mathrm{L}$ ) seed collected from three different districts of Bangladesh. In addition, this oil can be used after refining or as crude oil in soap making, cosmetics products etc. even as animal feed. Additionally, higher saponification value, iodine value and unsaturated fatty acid make the oil suitable for the manufacture of paints, varnishes' and soaps etc. Moreover, higher content of linoleic $\left(\mathrm{C}_{18: 2}\right)$ acid of mulberry (Morus alba $\mathrm{L}$ ) seed oil may be evaluated as a good source of essential fatty acid.

\section{References}

[1] Bangladesh Bureau of Statistics (BBS), Monthly Statistical Bulletin, Bangladesh, June-2013, pp. 1-196.

[2] M. F. Ramadan, G. Sharanabasappa, Y. N. Seetharam, M. Seshagiri and J. T. Moersel. 2006. Characterization of fatty acids and bioactive compounds of Kachnar (Bauhinia purpurea L.) seed oil. Food Chem 98:359-365.

[3] Anonymous. The wealth of India. A Dictionary of Indian Raw Materials and Industrial Products, Publications and Information Directorate CSIR, New Delhi, Vol. VI, P. 436, 1950.

[4] I. Dini, G. C. Tenore and A. Dini. 2008. Chemical composition, nutritional value and antioxidant properties of Allium caepa L. var. tropeana (Red onion) seeds. Food Chem 107: 613-621.

[5] Son Sonia Ben Temime, Taamalli Wael, Baccouri Bechir, Abaza Leila, Daoud Douja and Zarrouk Mokhtar. 2006. Changes in olive oil quality of chétoui variety according to origin of plantation, J Food Lipids 13: 88-99.

[6] J. A. Kichener. 1973. Findlay's Practical Physical Chemistry, $9^{\text {th }}$ Edn. P. 201.
[7] I. Devine and P. N. Williams. 1961. The chemistry and technology of edible oils and fats, pergamon press, New York, Oxford, London, Paris, pp. 122-134.

[8] K. A. Williams. 1966. Oils, Fats and Fatty Foods, $4^{\text {th }}$ Edn. I of A Churchill Ltd. London, PP. 124-380.

[9] M. A. Gofur, M. S. Rahman, G. M. Ahmed, A. Hossain and M. E. Haque. 1993. Studies on the characterization and glyceride composition of Tobacco (Nicotiana tabacum L) seed oil. Bangladesh J Sci Ind Res 28: 25-31.

[10] G. Rouser and G. Kritchevsky. 1967. Lipid chromatographic analysis, vol. 1, pp. 99-112.

[11] M. H. Ali, M. S. Rahman, G. M. Ahmed, M. A. Hossain and M. M. Uddin. 1996. Studies on the fatty acid and glyceride compositions of Nim seed oil. Bangladesh J Sci Ind Res 31: 99-105.

[12] R. K. Das. 1989. Industrial Chemistry, Part-2, Kalyani Publishers, New Delhi, India, 279.

[13] M. S. Rahman, M. A. Hossain, G. M. Ahmed and M. M. Uddin. 2007. Studies on the characterization, lipids and glyceride compositions of sesame (Sesame indicum L) seed oil. Bang J Sci Ind Res 42: 67-74.

[14] http://en.cnki.com.cn/Article_en/CJFDTOTALZLYX804.010.htm (accessed, 16/06/2014).

[15] T. P. Hilditch. 1949. The Industrial chemistry of Fats and Waxes. Bailliere Tindall and Cox. London, $3^{\text {rd }}$ ed., p. 80.

[16] M. Rafiquzzaman, M. A. Hossain and AJM. M Hasan. 2006. Studies on the characterization and glyceride composition of safflower (Carthamus fintorius) seed oil. Bang J Sci Ind Res 41: $235-238$.

[17] K. F. Mattil, F. A. Norris, A. J. Stirton and D. Swern. 1951. Bailey's industrial oil and fat products $3^{\text {rd }}$ edn. Interscience Publishers. New York, p. 212.

[18] Cynthia Nkolika Ibeto, Chukwma, Obiajulu Benedict Okoye and Akuzuo Uwaoma Ofoefule. 2012 Comparative study of the physicochemical characterization of some oils as potential feedstock for biodiesel production. ISRN Renewable Energy, 2012: 1-6.

[19] V. A. Sodeke. 2005. Extraction of oil from watermelon seed and analysis of food. Quaternary Sci Rev 7: 25-30.

[20] Umit Gecgel, Serap Durakli Velioglu and Hasan Murat Velioglu. 2011. Investigating some physicochemical properties and fatty acid composition of native black mulberry (Morus nigra L.) seed oil. J Am Oil Chem Soc 88: 1179-1187. 